\title{
LA MIRADA DE NGENECHEN. REPRESENTACIONES ANFIBIOMORFAS APLICADAS AL PASTILLAJE EN LA ALFARERÍA DE LA PATAGONIA NOROCCIDENTAL ARGENTINA.
}

\author{
Alberto Enrique Pérez \\ Universidad de Buenos Aires. FHN Félix de Azara, Parque Nacional Lanín.Perito Moreno esq. Elordi \\ (8370) San Martín de los Andes, Neuquén. Mail:arqueo.meliquina@gmail.com \\ Presentado el: 10/03/2009 - Aceptado 13/07/2009

\section{Resumen} \\ Nuevos hallazgos de alfarería prehispánica en la localidad de San Martín de los Andes, \\ departamento Lácar, provincia de Neuquén, muestran la presencia de atributos decorativos zoomorfos \\ abstractos o anfibiomorfos (ranas) estilizados en proximidad de ambientes fluviales. Estos atributos \\ modelados fueron caracterizados históricamente como "mamelones", en referencia a atributos sexuales \\ femeninos y símbolos de fertilidad. Sin embargo, este tipo de decoración modelada, muy bien conocida \\ en el territorio Centro Sur de Chile en la alfarería pre y post hispánica, se presenta como la gradual \\ abstracción de representaciones anfibiomorfas hasta culminar preservando sus rasgos más distintivos, \\ sus ojos, caracterizados técnicamente como protúberos. La representación del anfibio, además de un \\ atributo estilístico, es postulada como evidencia de elementos de la cosmovisión compartidos por las \\ poblaciones cazadoras-recolectoras complejas que ocupaban ambas vertientes de la Cordillera de los \\ Andes entre los siglos III y XVIII de nuestra era.
}

Palabras claves: Norpatagonia, alfarería, protúberos, anfibiomorfos.

\begin{abstract}
New findings in pre-hispanic pottery from San Martin de los Andes, Lacar district in Neuquén, allow us to relate the presence of decorative stylized zoomorphic attributes or abstract amphibiomorphs (frog) in fluvial environments. These attributes were historically characterized as "mamelones" in reference to female sexual attributes and symbols of fertility. However, this type of decorating pattern, which is very well known in the territory of South Central Chile in pre and post hispanic pottery, can be seen as the gradual abstraction of amphibiomorphs features emphatizing their distinctive detail, his eyes, which are characterized technically as protúberos. Besides the representation of amphibian as stylistic attribute, it is postulated as evidence of the hunter-gatherer worldview who occupied both slopes of the Andes between third and eighteenth centuries of our era.
\end{abstract}

Keywords: Northern Patagonia, pottery, protúberos, amphbiomorphs.

\section{Introducción}

En el ejido urbano de la localidad de San Martín de los Andes, y otros sectores del departamento Lácar dentro del Parque Nacional Lanín, provincia de Neuquén, se han recuperado artefactos cerámicos con decoración modelada en asas por aplicación de relieve. 
Estos atributos carecen de funcionalidad clara y, por lo tanto, los consideramos no utilitarios, ornamentales o decorativos. Su presencia no es una novedad, ya que cuentan con varias menciones previas, donde ha sido interpretado como un atributo de fertilidad femenina, $y$ una suerte de fósil guía de ocupaciones o influencias araucanas tardías (postcoloniales) en la Patagonia noroccidental argentina. Se trata de apliques de arcilla modelados de forma circular, cónica o subrectangular, agregados por pastillaje de a pares transversalmente dispuestos y separados uno de otro en el segmento superior de asas, o dispuestos en los bordes laterales de las asas acintadas, proyectados hacia arriba (Figura 1).

A partir del estudio de nuevos hallazgos en el bosque meridional neuquino proponemos realizar una síntesis de las referencias de este atributo en el territorio patagónico. Nuestro objetivo es actualizar su distribución espacial y temporal, para luego contextualizarlo adecuadamente y compararlo con el registro arqueológico de localidades vecinas, incluyendo a ambas vertientes de la Cordillera de los Andes.

\section{Antecedentes}

La presencia de alfarería con decoración por aplicación de relieve es escasamente conocida en el territorio patagónico, sin embargo, su primera mención corresponde a las más tempranas descripciones de alfarería de Patagonia por Verneau en 1903, donde se refiere a un tiesto con asa "mamelonar" encontrado en Gaiman, en la costa Chubutense. Posteriormente, Vignati describe un asa con decoración geométrica incisa y dos prominencias achatadas, a manera de mamelones, entre los artefactos descubiertos en el sitio Paradero de Yankín, en

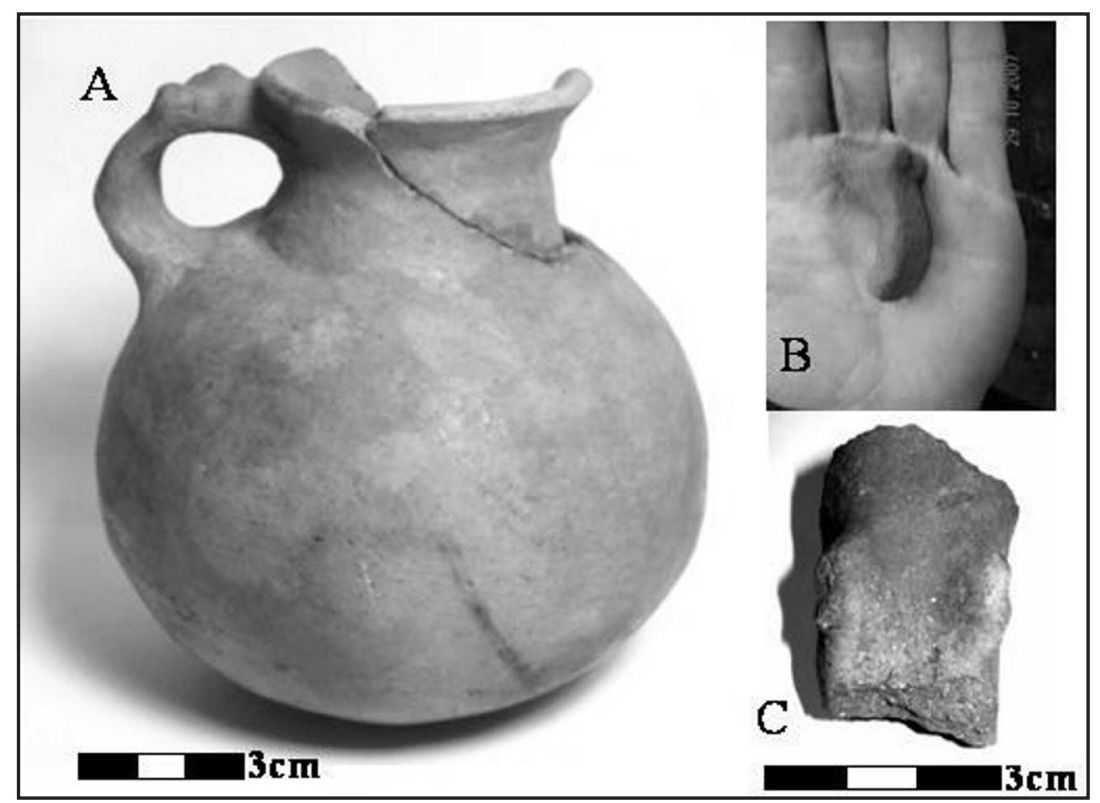

Figura 1: A- Vasija con protúberos modelados en asa de cerro Comandante Díaz, B- asa con protúberos de cerro Curruhuinca y C-asa con protúberos de sitio Lago Meliquina, Faja Superior. 
proximidades del Cementerio Río Limay, sobre la margen oriental del río, provincia de Río Negro (Vignati 1944: 147, fig. 9).

Años más tarde, Schobinger describe una importante cantidad de artefactos cerámicos con estas ornamentaciones para la provincia de Neuquén. Describe vasijas con mamelones en sus asas en la localidad de Loncophue. En Las Lajas, prominencias o mamelones en el asa de un botellón, y la parte superior de ambas asas de una olla grande recuperada en el cerro Media Luna, ambos en el departamento Picunches. En el lago Aluminé, sobre la Angostura, una olla que presenta dos crestas en la parte superior de cada asa. En la zona de los Lagos Aluminé y Pilhué describe dos asas con prominencias en la parte superior. Más al sur, en el Cordón de Chapelco y la Vega Maipú, en proximidad y con excelente vista del lago Lácar, arroyos y mallines, describe una olla y un fragmento lateral de olla, ambos con mamelones en la parte superior de sus asas (Schobinger 1958: 27, 41, 71).

Posteriormente, Bórmida (1964) se refiere a un fragmento de asa con dos "pequeñas eminencias" en el sector superior procedente de la provincia de Río Negro. Años después, Bellelli compila los hallazgos superficiales y estratigráficos conocidos hasta fines de la década de 1970 de la región patagónica extrandina. Incluye los materiales descritos por Veneau (1903) y Bórmida (1964), caracterizándolos en su análisis como motivos pertenecientes al grupo L, o Mamelones, correspondiente a una modalidad decorativa realizada por modelado y altorrelieve cuya distribución geográfica se limita al norte de la Patagonia (Bellelli 1980: 207). Hajduk y Albornoz (1999: 381) describen dos fragmentos de asas verticales con aplicaciones al pastillaje, uno de los cuales presenta mamelones cónicos, de pasta beige, rojiza y uniforme en el Componente Cerámico Tardío del sitio Valle Encantado 1. En la localidad arqueológica Piedra del Águila describen un asa en cinta con mamelones de sección elipsoidal en el sitio Zaina Yegua 5 (Senatore 1996:134. fig. 4).

\section{Otros hallazgos que versan sobre decoración por relieve}

Adam Hajduk refiere en su descripción de vasijas singulares de la provincia de Neuquén, a la pieza $\mathrm{N}^{\mathrm{o}} 2$, como jarra con decoración negra sobre rojo (Hajduk 1978: figura 3 y 4), procedente de Las Lajas, con apéndice cefálico zoomorfo y rasgos al pastillaje, presentando "ojos mamelonares", orejas y un pico chato, pero que luego el autor refiere por su morfología a la posible representación de un perro (Hajduk 1978:105). La pieza $\mathrm{N}^{\circ}$ 5, caracterizada como Jarro-pato con decoración negra sobre ante y sobrepintado en colorado procedente de Las Lajas, Loncopué (departamentos de Picunches y Loncopué) presenta un asa semi-puente en plano oblicuo, de sección subrectangular culminando en parte del apéndice caudal con pequeños mameloncitos salientes agregados al pastillaje (véase Hajduk 1978:107). En el sitio Montículo Angostura, niveles Moquehue I y II, se menciona la presencia de decoración por agregado de material o pastillaje como "botones" (Adán y Alvarado 1999; Hajduk 1978). En el área Piedra del Águila se describen varios conjuntos con este atributo, como un asa maciza mamelonar datada en $910 \pm 50$ años A.P. en el sitio Piedra del Águila 11 (Senatore 1996:133, fig. 2d) y un asa cilíndrica con mamelón en Cueva Epullán Grande, procedente de un subconjunto cerámico datada en ca. 1080 550 años AP (Senatore 1996: 135).

\section{Las investigaciones chilenas}

A partir de la recuperación de una importante cantidad de vasijas completas en casi 50 años de trabajo -aunque discontinúo-, en sitios chilenos, los investigadores han realizado 


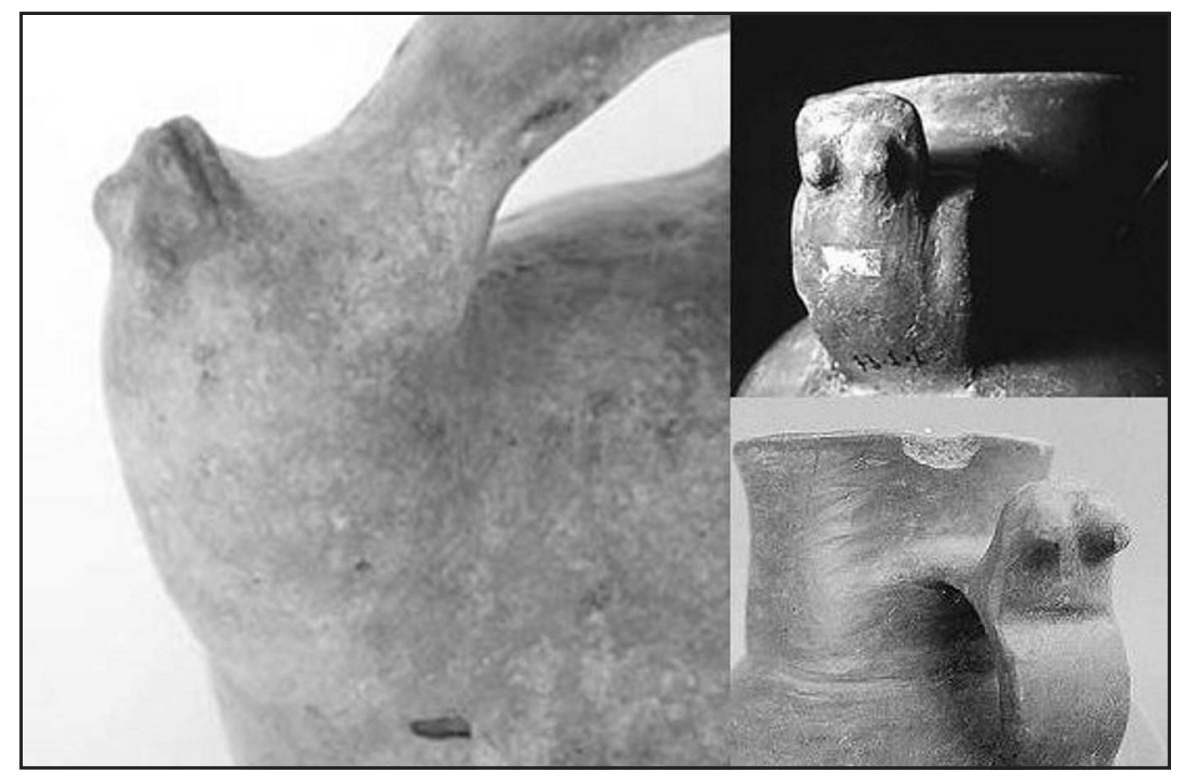

Figura 2: Representaciones anfibiomorfas del Complejo Pitrén, procedentes del la región Centro Sur de Chile.

una caracterización de los principales morfotipos de vasijas y modalidades estilísticas, incluyendo a esta decoración como "protúberos", parte componente del repertorio de las representaciones Anfibiomorfa naturalista y anfibiomorfa estilizada que caracterizan al complejo alfarero Pitrén, con registros desde el siglo III de nuestra era (Adán y Alvarado 1999).

Estas representaciones se asocian a buena parte de las categorías morfológicas de jarros asimétricos, generalmente con decoración modelada restringida al gollete cerrado opuesto al cuello, donde distinguen carita antropomorfa, anfibiomorfas naturalistas y anfibiomorfas estilizadas (Adán y Alvarado 1999: 252). Dentro de la decoración modelada del complejo Pitrén distinguen variantes, de las que sólo detallaremos las que son de interés inmediato para este trabajo. Las Variedades A: Figurativos zoomorfos en asa mango en piezas monocromas, asociadas solamente a impronta de hojas como otra técnica decorativa (motivos zoomorfos indeterminados) (Adán y Alvarado 1999: 254).

Variedad B: Figurativos anfibiomorfos como prolongación del asa, acompañada en ocasiones con decoración bícroma. Agregado por aplicación de una porción de arcilla aplanada adherida al extremo superior del asa en arco de correa de los jarros, con adhesión de dos protúberos a modo de ojos y, eventualmente, una incisión alargada en el extremo para configurar la boca. Según estos autores, se elabora mediante la técnica de agregación y sustracción de material, y representa la estilización del motivo anfibiomorfo. Este rasgo se mantiene vigente hasta periodos más tardíos en urnas y jarros asimétricos del Complejo El Vergel (Adán y Alvarado 1999: 254). 
Variedad C: Figurativo anfibiomorfo en diámetro máximo del cuerpo de las piezas monocromas. Consiste en aplicar en el diámetro máximo de la pieza dos protúberos a modo de ojos y una porción alargada a modo de boca, ambas por pastillaje (Adán y Alvarado 1999: 254).

Variedad D: Figurativo anfibiomorfo "naturalista" en jarros asimétricos. Modelado, cuerpo subcilíndrico emplazado en lado opuesto del gollete. Compuesta por una figura tridimensional hueca que tiene en el extremo superior tres porciones de material que representan los rasgos estandarizados anfibiomorfos, es decir, ojos y boca, la que frecuentemente va acompañada de un abultamiento. Estos rasgos también serían elaborados por aplicación y agregación de material (Adán y Alvarado 1999: 255). En suma, el gran número de vasijas recuperadas en el Centro Sur de Chile ah permitido reconstruir la sistematización y abstracción de la representación de la figura del anfibio, específicamente ranas y/o sapos, los que en algunos casos culminarían en una cabeza esquematizada con dos protuberancias a modo de ojos o, simplemente, los ojos ubicados en la misma posición que ocuparan cuando la figura guarda mayor naturalismo (véase también Mera y Lobos 2008).

\section{Descripción de nuevos hallazgos en San Martín de los Andes}

Contamos con un número mínimo de cuatro vasijas con protúberos en sector superior de asas procedentes de tres sitios arqueológicos en San Martín de los Andes. El único hallazgo estratigráfico proveniente de excavaciones sistemáticas en la región corresponde a la Cuadrícula AI, Capa 2 de la Faja Superior de un sitio residencial a cielo abierto denominado Lago Meliquina (Figura 1 C), a orillas del lago homónimo, aproximadamente $40^{\circ} 19^{\prime} \mathrm{S}$ y $71^{\circ}$ $19^{\prime} \mathrm{O}$, datado mediante ${ }^{14} \mathrm{C}$ en $730 \pm 80$ años AP (LP 1559, carbón vegetal, Pérez 2006).

Otros hallazgos provienen de trabajos de rescate en pleno ejido urbano de San Martín de los Andes, uno de la ladera oriental del cerro Curruhuinca aproximadamente $40^{\circ} 08^{\prime} \mathrm{S}$ y $71^{\circ}$ $21^{\prime} \mathrm{O}$, y otro de la ladera occidental del cerro Comandante Díaz, frente al primero, en la margen opuesta del mismo valle, aproximadamente $40^{\circ} 09^{\prime} \mathrm{S}$ y $71^{\circ} 20^{\prime} \mathrm{O}$ (Figura 1 , imágenes B y A respectivamente). En ambos casos, descubiertos accidentalmente e intervenidos en forma de rescate por el área Patrimonio Histórico y Ciencias de la Municipalidad de San Martín de los Andes. Se trata de emplazamientos con una vista privilegiada de cursos de agua, el primero del arroyo Pocahullo y lago Lácar, mientras que el segundo se emplaza en un lugar que hoy día es un mirador de uso turístico por contar con una visión panorámica de todo el lago Lácar hasta lago Nonthué y cordones montañosos de Chile. En ambos casos la alfarería corresponde a vestigios de acompañamiento funerario, el primero más dudoso, ya que si bien se encontró asociado a restos humanos, el material estaría depositado en un contexto secundario por procesos gravitacionales, en un cono aluvional bajo la ladera un cerro y por ende, sujeto a múltiples factores postdepositacionales (Pérez 2007). En el segundo caso, los materiales estaban en un contexto primario, acompañados de varios artefactos (lítico, cerámico y óseo), junto a los restos de un individuo juvenil bastante completo (Pérez y Reyes 2009).

Según Schobinger, estos mamelones son un rasgo decorativo muy común en la araucania chilena (Schobinger 1958). Menghín refiere al registro de asas provistas de mamelones como frecuentes del Neoaraucano o Pucopiense de la segunda mitad del siglo XVIII (Menghin 


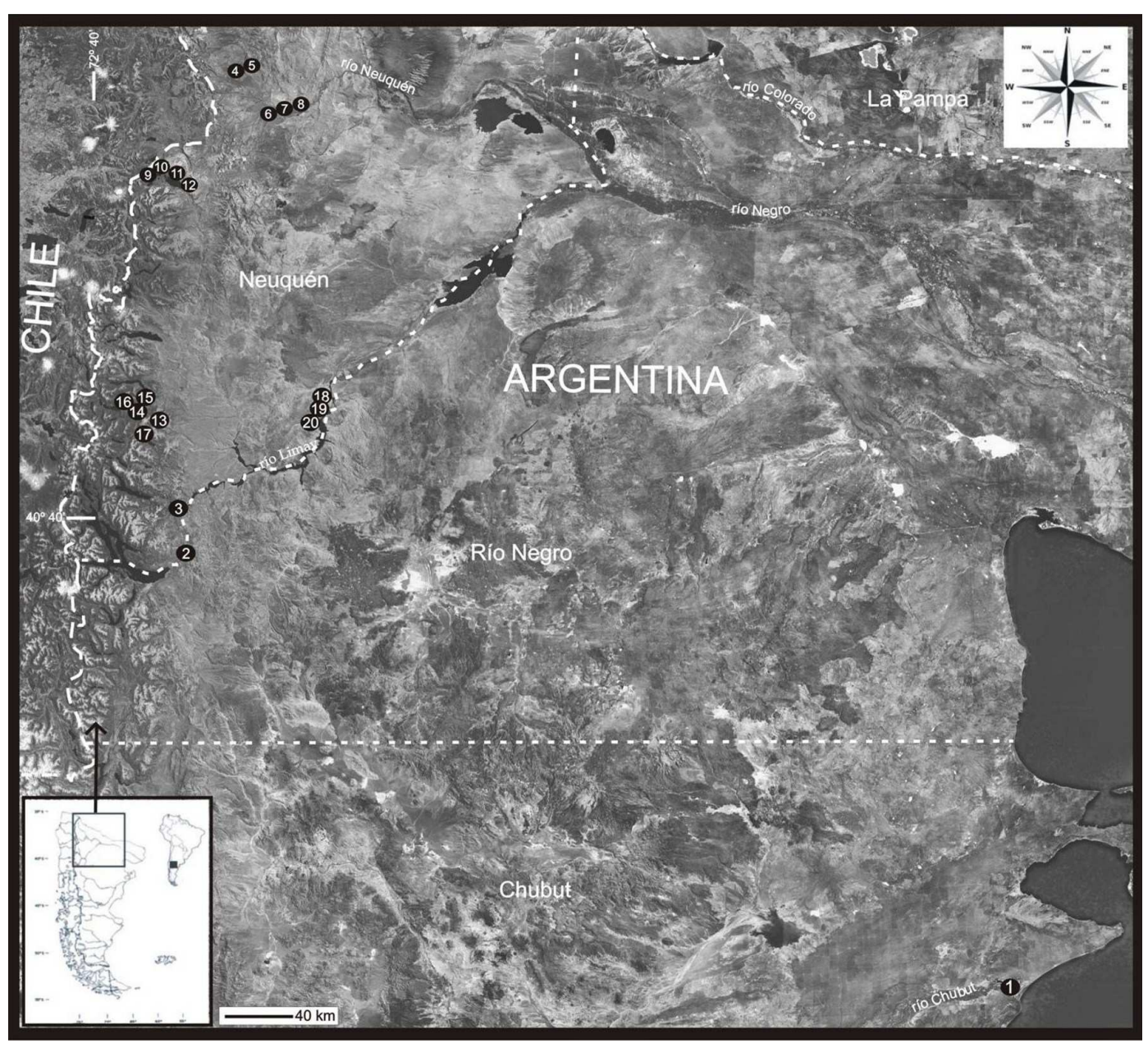

Figura 3. Sitios con presencia de aplicaciones al pastillaje sobre asas: 1- Gaiman , 2Paradero de Yankín, 3- Valle Encantado 1, 4 y 5- Loncophué, 6 y 7- Las Lajas, 8-Cerro Media Luna, 9- La Angostura, 10- Lago Alumine-Pilhue, 11-Montículo Angostura, 12Cordón Chapelco, 13-Cerro Comandante Díaz, 14-Vega Maipú, 15-Cerro Curruhuinca, 17lago Meliquina, 18- Piedra del Aguila 11; 19-Zaina Yegua, 20- Cueva Epullan Grande

1962:49). Posteriormente, Bórmida las asocia a su Norpatagoniense III, agregando que estos atributos son frecuentes en las jarras araucanas postcolombinas (Bórmida 1964). Sobre la base de estas consideraciones, las más recientes contribuciones de Goñi (1992) en sitios tardíos del valle de Malleo, y los de Senatore (1996) para el área Piedra del Águila, ambos en la provincia de Neuquén, se refieren a las asas con mamelones como tardías (véase Aldazabal y Eugenio 2004, 2009) y a sus portadores como poblaciones araucanas o de posible origen transcordillerano.

\section{Discusión}

Estos atributos aplicados al pastillaje han sido descrito en Norpatagonia argentina hace más de un siglo (Verneau 1903), aunque denominado de múltiples formas tales como 
mamelones, apéndice, prominencias, eminencias, crestas, etc. Originariamente se describe o representa como apéndices pares ubicados en forma transversal y paralela en la parte superior de asas verticales, tanto en jarras como en ollas. Técnicamente, se trata de una modalidad decorativa realizada por relieve (Bellelli 1980) y su nombre más genérico ha sido el de "mamelones", aduciendo a un símbolo de fertilidad femenina, seguramente interpretado por analogía durante principios del siglo XX con contextos de la contemporánea arqueología europea. Posteriormente el término fue generalizado y extendido, utilizado para describir apéndices individuales y hasta ojos de representaciones modeladas de mamíferos.

Al occidente de la Cordillera de los Andes, en latitudes similares, los investigadores chilenos han caracterizado este rasgo con un término más neutral, como "protuberos", integrante destacado de las modalidades estilísticas que caracterizan el amplio repertorio del período alfarero más temprano del sur de Chile, conocido como Complejo Pitrén (Menghin 1962; Aldunate 1989; Adán y Alvarado 1999). Recientemente, estos protúberos han sido incluidos como una modalidad de la representación anfibiomorfa que caracteriza a este complejo Alfarero, bajo la denominación de rasgo "ojos saltones", aduciendo a la característica exoftalmia de estos anfibios, la que les ofrece una visión periscópica (Mera y Lobos 2008).

Las representaciones anfibiomorfas componen parte del repertorio de las vulgarmente denominadas "vasijas efigie" conocidas para el centro sur de Chile. Estas generalmente tienden a ser del color natural de la arcilla, o sea que carecen de engobes o pinturas, y presentan formas modeladas antropomorfas, fitomorfas y zoomorfas, manteniéndose vigentes algunos de estos diseños entre los alfareros mapuches actuales. Entre estos se destacan algunas vasijas cuya forma remite al cuerpo de un anfibio, específicamente a batracios, o suelen llevarlo esquemáticamente transformado en su asa (véase también Mera y Lobos 2008). La representación de ranas y sapos podría estar vinculada al "Ngenko", el "dueño de las aguas" en lengua Mapuche, usualmente representado por la figura de este animal por los pueblos mapuches históricos y actuales.

Recientes estudios realizados por investigadores chilenos han postulado la presencia de elementos destacados en la alfarería Pitrén que remiten a la fertilidad, como los apéndices palmares en la figura del anfibio (Mera y Lobos 2008). Si bien su profundización excede los objetivos de este trabajo, es de sumo interés además el estudio sobre las propiedades toxicológicas, alucinógenas y medicinales de estos anfibios, ya que su uso por pueblos mapuches históricos cuenta con referencias etnográficas detalladas (Mera y Lobos 2008; Pérez 2010).

\section{Consideraciones finales}

Se observa una representación más acentuada de los protúberos en asas verticales sobre vasijas sin pintura o asociadas a impronta de hojas asignables a la Variedad B en sitios meridionales como los lagos Lacar y Meliquina. En el caso de este último, asociadas a vasijas decoradas con pintura geométrica negra sobre engobe colorado (Pérez 2006; Pérez y Reyes 2009). Dentro del repertorio de las vasijas descritas tanto por Schobinger (1958) como por Hajduk (1978) en los hallazgos más septentrionales, como Loncophe, Las Lajas y AlimineMoquehue, se observan claramente las representaciones de protúberos correspondientes a las Variedades $\mathrm{C}$ y D, incluso algunos asignables potencialmente a la A, junto a la presencia 
de decoración de "lentejuelas al pastillaje" descritos también en conjuntos habitacionales Pitrén de la región de Calafquén (Reyes 2009).

De esta forma, en la región surneuquina encontramos representadas todas las variantes del complejo Pitrén que incluyen la aplicación de material modelado y agregado al pastillaje. En los sitios de San Martín de los Andes predominan las asignables a la variedad B (sensu Adán y Alvarado 1999), donde los protúberos representan los ojos de la figura anfibiomorfa, predominando las formas estilizadas, caracterizadas mas recientemente como rasgo "ojos saltones" por Mera y colaboradores (Mera y Lobos 2008) (Figura 2). De modo que este atributo modelado, tan generalizado operativamente como "mamelones" en los estudios argentinos, no guarda ninguna relación con atributos sexuales femeninos como fuera históricamente atribuida, hasta involuntariamente, en estudios previos. Por lo que proponemos utilizar el termino mas neutral de protúberos en las representaciones mas abstractas, e incluso al rasgo "ojos saltones" en las mas naturalistas, proyectándonos así hacia estudios macroregionales, y contribuyendo a los trabajos en curso que incluyen a ambas vertientes de la cordillera andina norpatagónica, al menos en momentos alfareros, como partes integradas un mismo espacio ecológico (véase Pérez y Reyes 2009)..

Si bien han existido representaciones femeninas dentro del repertorio de los cazadoresrecolectores complejos del centro sur de Chile, generalmente se encuentran agregadas por pastillaje al cuerpo, o limitadas al cuello en el caso de rostros y cabezas, correspondiendo mayormente a representaciones naturalistas. Su registro en asas, aunque existente, es escaso (véanse Hajduk 1985, figura XVIII B, lamina D) .

Estos atributos (protúberos) presentan una distribución exclusivamente Norpatagónica (véase también Bellelli 1980), restringida al Sur y Oeste respectivamente de la cuencas de los ríos Neuquén y Limay al sur de la provincia de Neuquén y con mayor frecuencia en proximidad de ambientes lacustres boscosos cordilleranos. El único hallazgo de Chubut, podría considerarse raro o atípico.

Existe una clara correspondencia entre los lugares donde aparecen vestigios de alfarería con estos atributos y ciertos elementos fundamentales del paisaje y el ambiente relacionados ecológicamente. Se trata de su asociación con recursos hídricos, o paisajes húmedos, hábitat natural de los anfibios. En los casos aquí expuestos a modo de antecedente observamos que la mayoría, sino todos estos artefactos con protúberos, han sido recuperados en inmediata proximidad de cuerpos de aguas estables. Otro aspecto interesante es que en la mayoría de los casos se trata de morfotipos de recipientes vinculados a la contención y procesamiento de líquidos.

La decoración anfibiomorfa en la cerámica de la Patagonia Noroccidental Argentina es un elemento que nos permite postular una modalidad singular de alfarería para la región lacustre boscosa pre y cordillerana. Esta es diferente a la observada hacia el norte del río Negro (Prates 2008), río Colorado (Martínez 2004, 2006) y otros sectores costeros de Norpatagonia (Bórmida 1964; Bellelli 1980), y está más emparentada a las diversas variantes que caracterizan a la alfarería de la región Centro Sur de Chile (Aldunate 1989; Adán y Alvarado 1999; Pérez y Reyes 2009), donde se describen al menos 3 tipos de asociaciones entre artefactos cerámicos en los yacimientos con alfarería Pitrén (Adán y Alvarado 1999). En nuestra área de estudio hay elementos que refieren tanto a las asociaciones del Valle 
Central, próximo al río Cautín, como a las del Ámbito Lacustre Precordillerano Occidental (sensu Adán y Alvarado 1999). Por ejemplo, el hallazgo de una vasija con impronta de hojas y protúberos en sector superior de asa recuperada en contextos funerarios del sitio Cerro Comandante Díaz (Pérez y Reyes 2009) cuenta con un único registro similar en el sitio habitacional Liucura-1, en cercanías del lago Villarrica, IX Región de Chile (Donoso y Gallego 2008, en Pérez y Reyes 2009). Esto, sumado a la posible adscripción de varios artefactos actualmente bajo estudio-, recuperados en Lago Meliquina, a la variedad Trínglo del complejo Pitrén característica de Lago Ranco, Chile remite nuevamente a una gran diversidad de estilos y una amplia distribución territorial, pero predominando las asociaciones caracterizadas para el Ámbito Lacustre Precordillerano Occidental. Según Adán y Alvarado (1999), correspondiente a la contrapartida occidental a la fase oriental cordillerana del Complejo Pitrén según postula Aldunate (1989).

\section{Conclusiones}

Los atributos en la decoración de la alfarería Patagónica históricamente denominados "mamelones", son en realidad parte del repertorio de representaciones anfibiomorfas del complejo alfarero Pitrén y posteriormente Vergel, ambos característicos del ámbito Centro Sur de Chile. Por lo tanto, la antigüedad de este atributo es mayor a la comúnmente asociada en Argentina, y de ninguna manera es indicador de contacto transcordillerano o de cronologías históricas sin evidencia adicional que lo ratifique. En la vertiente oriental cordillerana a similares latitudes, contamos con el registro de producción local de alfarería que incluyó este tipo de atributo en San Martín de los Andes, para 1.250 50 años AP. La figura del anfibio, conocida en lengua Mapuche como Ngenko o gnenco, suele ser una denominación que se le da también históricamente al "Ser Supremo", junto con las de "Ngenechen" y "Ngenemanpun". También referida a un espíritu protector o "Ngen" de las aguas (Grebe 1988; Mera y Lobos 2008), remitiéndonos con ello a una clara y significativa referencia simbólica además de la evidente ecológica. Todo esto nos permite postular, además de un espacio ecológico en común, la posible práctica de extracción y uso de toxinas (medicinas, alucinógenos y venenos) de batracios, junto a la presencia de atributos estilísticos y elementos de la cosmovisión compartidos por las poblaciones cazadoras-recolectoras complejas que están ocupando ambas vertientes de la Cordillera de los Andes entre los siglos III y XVIII de nuestra era.

\section{Agradecimientos}

A Rodrigo Mera por facilitarme gentilmente sus escritos e imágenes. A la Estancia Parque A. Diana S.A. por su constante apoyo. Este trabajo forma parte del proyecto UBA 840162, Arqueología del bosque meridional neuquino y su relación con sitios del área Paso Limay, estepa rionegrina y sectores transicionales. A los evaluadores anónimos por sus valiosos comentarios.

\section{Bibliografía citada.}

Adán, L. y M. Alvarado

1999. Análisis de colecciones alfareras pertenecientes al complejo Pitrén: Una aproximación desde la arqueología y la estética. En: Soplando en el viento. Actas III Jornadas de Arqueología de 
la Patagonia. pp. 245-268. Editado por J.B Belardi, P. M Fernández, R. A Goñi, A.G Guráieb y M. De Nigris. Universidad Nacional del Comahue e Instituto Nacional de Antropología y Pensamiento Latinoamericano. Neuquén-Buenos Aires.

Aldazabal, V.y E. Eugenio.

2004. La cerámica del Sitio Rincón Chico 2. En: Contra viento y marea Arqueología de Patagonia, pp. 671-677. Editado por M. Civalero, P. Fernández y A. Guráieb. Instituto Nacional de Antropología y Pensamiento Latinoamericano y Sociedad Argentina de Antropología. Buenos Aires.

2009. Entre el fuego y el juego. La cerámica del sitio Rincón Chico 2/87. Arqueología de rescate de Rincón Chico, provincia del Neuquén, pp. 164-186..Crivelli Montero, E.A.; M.

Fernández y M.S. Ramos compiladores. Editorial Dunken. Buenos Aires

Aldunate, $\mathrm{C}$.

1989. Estadio Alfarero en el sur de Chile. En: Culturas de Chile. Prehistoria, pp. 329-348. Editado por J. Hidalgo, V Schiappaccase, H. Niemeyer, C. Aldunate e I. Solimano. Editorial Andrés Bello. Santiago.

Bellelli, C.

1980. La decoración de la cerámica gris incisa de la Patagonia, República Argentina.

Revista del Museo Paulista. XXVII:199-225.

Bórmida, $\mathrm{M}$.

1964. Arqueología de la costa Norpatagónica. Trabajos de Prehistoria. Madrid.

Goñi, R.

1992. Arqueología de sitios tardíos en el valle de Malleo. Relaciones de la Sociedad Argentina de Antropología, Nueva Serie, Tomo XVII (1):37-67.

Grebe, M.E.

1988. Algunos paralelismos en los sistemas de creencias Mapuche: los espíritus del agua y de la montaña. Boletín del Museo Regional de la Araucanía 3:71-78. Chile.

Hajduk, A.

1978. Excepcionales ceramios de la provincia del Neuquén. Presencia de alfarería con decoración por pintura resistente en la provincia de Neuquén. Algunas consideraciones en torno a ella. Revista del Museo Provincial 1:103-121. Neuquén.

1985. Representaciones antropomorfas en la alfarería arqueológica neuquina (Argentina). Comunicaciones Científicas del Museo de la Patagonia "Francisco P. Moreno". Serie Antropología, Año 1, No 1: 1-20. San Carlos de Bariloche.

Hajduk, A. y A. M. Albornoz

1999 EL sitio Valle Encantado I. Su vinculación con otros sitios: Un esbozo de la problemática local diversa del Nahuel Huapi. Soplando en el viento... Actas de las Terceras Jornadas de Arqueología de la Patagonia, pp. 371-391. Editado por J. B. Belardi, P. M. Fernández, R.A. Goñi, A. G. Guráieb y M. De Nigris. Universidad Nacional del Comahue e INAPL. Neuquén-Buenos Aires. 
Martínez, G.

2004. Resultados preliminares de las investigaciones arqueológicas realizadas en el curso inferior del río Colorado. En: Aproximaciones contemporáneas a la arqueología pampeana. Perspectivas teóricas, metodológicas, análisis y casos de estudio, G. Martínez, M. A. Gutierrez, R. Curtoni, M. Berón y P. Madrid (eds). Pp 275-292. Olavarría.

2006. Arqueología del curso inferior del río Colorado: estado actual del conocimiento. En: INCUAPA 10 años. Perspectivas contemporáneas en la arqueología pampeana y norpatagónica, G. Politis (ed.). Publicaciones INCUAPA-UNCPBA. Serie Monográfica No 5 , Olavaria (en prensa).

Mera, C. R. y G. A. Lobos

2008. Anfibios y reptiles en el imaginario cultural de Chile. En: Herpetología de Chile. Capitulo II: 55-76. Vidal, M.A. y A. Labra (eds). Science Verlag Ediciones. Chile.

Menghin, $\mathrm{O}$.

1962. Estudios de prehistoria Araucana. Acta Praehistórica III-IV. Centro Argentino de Estudios Prehistóricos. Buenos Aires.

Pérez, A. E.

2006. La Localidad Arqueológica “Lago Meliquina”, Dpto. Lácar, Neuquén. El registro arqueológico del interior y borde de bosque en Norpatagonia. Actas del XVI Congreso Nacional de Arqueología Chilena. Valdivia. En prensa.

2007. Vestigios arqueológicos en el ejido urbano de San Martín de los Andes, Neuquén. Informe presentado a la Subsecretaría de Cultura de San Martín de Los Andes. MS.

2010. Representaciones anfibiomorfas en el Centro Sur de Chile y ambientes lacustres precordilleranos de la Patagonia Septentrional Argentina. En: actas del Taller Binacional Argentino-Chileno Araucanía-Norpatagonia: cultura y espacio. San Carlos de Bariloche. Enviado para su publicación.

Pérez A. y V. Reyes

2009. Técnica improntas de hojas. Algunas reflexiones acerca de su novedoso registro en la vertiente occidental cordillerana. Magallania 37(1): 113-132.

Prates, L.

2008. Los Indígenas del Río Negro. Un enfoque arqueológico. SAA, Buenos Aires

Reyes, V.

2009. Microvariaciones en las cadenas operativas de producción cerámica durante el período alfarero tardío del área lacustre de los andes occidentales, lat $39^{\circ}$ Sur, Patagonia Septentrional. Arqueología de Patagonia. Una mirada desde el último confin (M. Salemme, F. Santiago, M. Álvarez, E. Piena, M. Vázquez y E. Mansur compiladores). Tomo 2: 1159-1176. Ushuaia. Editorial Utopías.

Senatore, $\mathrm{X}$.

1996. Tecnología cerámica en el Área de Piedra del Águila, provincias de Río Negro y Neuquén. Prehistoria 2: 127-147. Buenos Aires

Schobinger J.

1958. Hallazgos arqueológicos de la provincia de Neuquén. Lista descriptiva de material mobiliar. Anales de Arqueología y Etnología, Suplemento al Tomo XIII (Mimeografiado). Mendoza. 
Verneau, R.

1903. Les ansien patagons. Contribuition a l'etude des races precolombiennes de l'America du Sud. Impremerie de Monaco.

Vignati, M.A.

1944. Antigüedades en la región de los lagos Nahuel Huapi y Traful. Notas del Museo de La Plata Tomo IX, Antropología, Nº 28:143-149. 